\title{
Identidade profissional docente: concepções de futuros professores
}

\author{
Eliane Paganini da Silva ${ }^{1}$ \\ Amanda de Mattos Pereira Mano 2
}

\begin{abstract}
RESUMO
A identidade profissional docente pode ser compreendida no âmbito da construção do conhecimento social. Nesse particular, investigou-se a concepção de 65 estudantes do curso de Pedagogia de uma universidade pública, sendo 33 estudantes do primeiro ano e 32 do quarto ano, acerca dessa identidade específica. Os participantes responderam a um questionário aberto, com questões que versavam sobre a identidade docente, as quais foram analisadas qualitativamente, sendo enquadradas nos níveis de compreensão da realidade social.Os resultados mostraram que as respostas dos alunos do primeiro ano concebem que a profissão do professor está ligada ao amor e ao cuidado com as crianças, já os alunos do quarto ano compreendem que outros fatores concorrem para a execução do trabalho docente, tais como a necessidade de uma formação específica e da consideração dos processos de ensino e aprendizagem. Pretendeu-se com essa investigação compreender os processos de construção da identidade profissional nesse grupo específico, bem como promover discussões pertinentes à formação inicial de professores.
\end{abstract}

PALAVRAS-CHAVE: Identidade docente. Conhecimento social. Ensino Superior.

\section{Teacher professional identity: conceptions of future teachers}

\footnotetext{
ABSTRACT

Teacher's professional identity can be understood in the context of social knowledge construction. In this particular, we investigated the

${ }^{1}$ Doutora em Educação. Universidade Estadual do Paraná - Unespar, Apucarana, Paraná, Brasil. E-mail: eliane_ps@hotmail.com.

${ }^{2}$ Doutora em Educação. Universidade Estadual do Paraná - Unespar, União da Vitória, Paraná, Brasil. E-mail: amanda_mattosbio@yahoo.com.br.
} 
conception of 65 Pedagogy course students of a public university, being 33 first year students and 32 of the fourth year, about that specific identity. Participants answered an open questionnaire, with questions that dealt with the subject matter mentioned, which were qualitatively analyzed, being framed in the levels of social reality understanding. The results show that answers of first-year students conceive teacher's profession as linked to love and children care, while the fourth-year students understand that other factors contribute to teaching work execution, such as the need for specific formation and consideration of teaching and learning processes. The aim of this research was to understand construction processes of professional identity in this specific group, as well as to promote discussions relevant to teacher's initial formation.

KEYWORDS: Teacher identity. Social knowledge. Higereducation.

$$
* * *
$$

\section{Introdução}

O termo identidade é de origem latina com significado de igualdade, continuidade. Esse termo polissêmico e o estudo de sua aquisição é discutido em domínios diferentes (sociológico, psicológico, antropológico, dentre outros) e considerando diferentes perspectivas.

Neste estudo, trataremos do conceito de identidade profissional docente e, para isso, o detalharemos por meio da compreensão de que essa identidade profissional específica, em sua constituição, abarca componentes de âmbito individual e coletivo.

No que se refere a dimensão individual, tem-se que a história da vida de um indivíduo é marcada por uma sucessão de mudanças de identidade, que envolvem, necessariamente, a substituição dos traços de identificações anteriores por novos (ROGERS, 1972). Sobre esse aspecto Giddens (2002) afirma que essa identidade pessoal é possível de ser observada nas reações das pessoas umas com as outras e na capacidade que cada indivíduo possui para manter algo particular, que diz respeito somente a ele. 
Nesse sentido, as identidades possuem sua subjetividade e particularidade (algo individual), mas que se constitui por meio das interações estabelecidas em um meio social.

Com relação aos aspectos coletivos, Berger e Luckman (1985) esclarecem que a identidade é um elemento chave da subjetividade e da sociedade, podendo ser reformulado a partir ou em função das relações sociais, sendo essa identidade construída por meio de um processo dialético entre o individual e o social.

Frente a tais conceituações, algumas indagações que perpassam a consolidação dessa identidade profissional específica, são: De que maneira professores em exercício concebem sua identidade profissional? Existem diferenças entre as concepções de professores que atuam nos diferentes anos da Educação Básica? E, ainda, os universitários das licenciaturas, isto é, os possíveis futuros professores, já possuem elementos dessa identidade profissional específica? Os elementos indicados por tais acadêmicos, no momento do ingresso no curso, são os mesmos dos alunos concluintes?

Acerca desses questionamentos os estudos de Paganini-da-Silva (2006; 2015) são investigações que vão ao encontro de algumas dessas questões. No entanto, em relação a identidade profissional de universitários de licenciatura não foi possível encontrar estudos que pudessem trazer elementos para compreensão de seu desenvolvimento.

Diante do exposto, esse artigo pretende explanar a respeito de uma investigação empregada com o objetivo de conhecer a concepção de licenciandos do curso de Pedagogia, de uma Universidade Estadual do Paraná, acerca da identidade docente, sob a ótica da construção do conhecimento social.

\section{A identidade docente e a construção do conhecimento social}

No início da análise sobre o conceito de identidade, a perspectiva da personalidade foi uma das únicas considerações aceitas e, até por volta dos 
anos 1960, o conceito de identidade se restringia ao campo da Psicologia. Apartir dessa década, começa a ser abordada sob o ponto de vista da Sociologia, entendendo que os indivíduos passam a ocupar uma posição enquanto atores das relações sociais.

A identidade individual ou pessoal está sempre sofrendo transformações e influenciando as experiências individuais e sociais. Nesse sentido, Vianna (1999), Pimenta (1997) e Dubar (1997) ressaltam uma relação estreita entre as identidades individuais e coletivas.

A identidade coletiva não é decorrência da individual, mas sem dúvida é marcada por certa dualidade: a identidade para si e a identidade para o outro (DUBAR, 1997) e ambas as identidades são essenciais para definir a identidade profissional do indivíduo.

A esse respeito Pimenta (1997) define que a identidade profissional do professor é construída sob aspectos sociais e internos a cada indivíduo, sendo esses atores e autores da própria história (com saberes, representações anseios, angustias) na constituição do ser professor.

Também influenciam e contribuem para a construção da identidade docente os antecedentes socioeconômicos, o tamanho da cidade natal, as experiências com outros professores, os conselhos de amigos, professores e pais, as identificações com um adulto admirado, as experiências passadas, além de aspectos profissionais específicos, tais como segurança, prestígio, salário e condições de trabalho,

Outro aspecto significativo acerca da identidade profissional dos professores é a imagem social do magistério, construída historicamente no âmbito coletivo, mas também a autoimagem construída no interior da carreira e profissão docente (NÓVOA, 1991). Para Arroyo (2000), as imagens e autoimagens dos professores são diversas e difusas, não existindo uma imagem única.

Para os professores de Educação Infantil, a imagem é difusa e pouco profissional; para as professoras primárias ela se torna mais definida já que existe um predomínio da "competência para o ensino das primeiras letras e 
contas, mas, sobretudo, o carinho, o cuidado, a dedicação e 0 acompanhamento das crianças" (p. 30); aflora entre os professores do segundo ciclo do Ensino Fundamental ( $6^{\circ}$ ao $9^{\circ}$ anos) e de Ensino Médio uma "indefinição profissional e pessoal que tem sua origem na indefinição social” (p. 31).

Paganini-da-Silva (2015) define a identidade profissional docente como um

processo contínuo, subjetivo, que obedece às trajetórias individuais e sociais, que tem como possibilidade a construção/desconstrução/reconstrução, atribuindo sentido ao trabalho e centrado na imagem e autoimagem social que se tem da profissão e também legitimado a partir da relação de pertencimento ao Magistério. (PAGANINI-DA-SILVA, 2015, p. $74)$.

Mas com relação à identidade dos alunos dos cursos de licenciatura e pedagogia o que se pode aferir é que, como ressaltam Pimenta e Libâneo(1999), as características desses cursos no decorrer do século XX possuem u a concepção tecnicista própria dos anos 70 que reduzia a formação do pedagogo à docência. Os autores evidenciam que desde os anos 1920 é possível perceber que os estudos pedagógicos perdem espaço para um entendimento de a Pedagogia ser resumida às contribuições da Psicologia e com o passar do tempo vai adquirindo "conotação de operacionalização metodológica do ensino" (PIMENTA; LIBÂNEO, 1999, p. 246).

Atualmente, a Resolução $\mathrm{N}^{\circ} 2$ de 1 de Julho de 2015, define as Diretrizes Curriculares Nacionais para a formação inicial em nível superior (cursos de licenciatura, cursos de formação pedagógica para graduados e cursos de segunda licenciatura) e para a formação continuada. Esse documento garante, em primeiro lugar, que os Cursos de Pedagogia tenham uma carga horária específica destinada às especialidades próprias da 
Pedagogia e, em segundo lugar, uma base comum que garante a docênciaou o ensinar como sendo o foco da identidade do educador.

Pimenta e Libâneo (1999) fazem algumas críticas a maneira como os cursos de Pedagogia eram estruturados até o final dos anos 90 (juntando as duas vertentes, a docência e a especialidade do ser pedagogo), perspectiva que foi mantida na Resolução supracitada. Independente dessas discussões a presente pesquisa tem como foco a docência tanto dos alunos iniciantes como dos concluintes dos cursos de Pedagogia.

Nesse estudo pretende-se discutir esses aspectos e a análise se dará tendo em vista as concepções e a identidade que esses estudantes possuem acerca da função docente e do futuro exercício profissional. Portanto, a definição de identidade está centrada nas funções e atribuições próprias do ser professor, que podem ser construídas no dia a dia da sala de aula, mas também no decorrer da formação inicial dos acadêmicos.

Nesse aspecto, esclarece-se que nos cursos de formação de professores todas as suas disciplinas devem colaborar para essa formação contribuindo com conhecimentos e métodos para fazer educação (PIMENTA, 2011).

Nóvoa (2009) ressalta a importância de captar o sentido de uma profissão e, portanto, o cerne da identidade profissional docente. Esse cerne está ou deve estar ligado à aprendizagem e aponta a importância de vislumbrarmos uma educação, uma escola que tenha uma organização centrada na aprendizagem. Além disso, apresenta a necessidade de se construir um conhecimento pessoal "no interior do conhecimento profissional”, algo que não esta apenas na matriz científica dos cursos de formação (NÓVOA, 2009, p. 14).

É possível olhar para o desenvolvimento profissional do professor também tendo como foco a teoria de Jean Piaget. O estudo de Chakur (2001) investigou três aspectos da profissionalidade docente, a identidade, a autonomia e a prática pedagógica. Tal pesquisa demonstrou que a identidade do professor não é questão de tudo ou nada, mas obedece a uma sequência de níveis de desenvolvimento. 
Igualmente, os resultados de Paganini-da-Silva (2006; 2015) indicaram níveis de tomada de consciência piagetiana para a identidade do professor. A autora (PAGANINI-DA-SILVA, 2006) teve como objetivo desvendar os aspectos relacionados à identidade e a crise de identidade docente de professores do segundo ciclo do Ensino Fundamental, sob o ponto de vista da teoria piagetiana, encontrando diferentes níveis de consciência acerca de sua identidade apontando para uma crise de identidade com relação à função docente.

Em outro estudo (PAGANINI-DA-SILVA, 2015), a autora investigou as concepções pedagógicas como parte constituinte da identidade docente e se os professores da Educação Básica tomavam consciência acerca desse aspecto do ser professor. A pesquisa ocorreu em duas escolas pedagogicamente distintas, uma escola denominada sócio construtivista e uma escola piagetiana. Os resultados indicaram que uma parte significativa dos participantes da escola piagetiana tomavam consciência do aspecto pedagógico como parte fundante da profissionalidade docente.

Jean Piaget (1886-1980) realizou pesquisas direcionadas ao conhecimento físico, lógico-matemático e ao conhecimento social. É bem verdade que o próprio Piaget não se aprofundou neste último campo de estudo, mas alguns teóricos, em continuidade às contribuições piagetianas, dedicaram־se a esta vertente.

Enesco et al. (1995) afirmam que o conhecimento social tem por objetivo explicar aquilo que é produzido em um contexto social e que, por isso, adquire sentido nas relações com os outros. Esse objeto de conhecimento pode se caracterizar por diferentes dimensões, sendo elas: o conhecimento do eu e dos outros (conhecimento psicológico ou pessoal), as relações interpessoais, os papéis sociais, as normas que regulam as condutas dentro do grupo social, bem como o funcionamento e a organização da sociedade.

Nesse sentido, a identidade profissional docente insere-se como uma temática inerente à construção social do conhecimento, porque conforme já 
afirmado, sua constituição e consolidação dá-se em processos de origem individual, mas que são fortemente influenciados pelas informações e vivências sociais.

Compreender esse fenômeno de natureza social, não é fácil. Quando trata-se do conhecimento social depara-se com um objeto de conhecimento muito complexo, com questões multifacetadas e ambíguas, uma vez que não é simplesmente absorver informações acerca de uma realidade social, mas, a partir de tais informações, interpretá-las e organizá-las na atribuição de significados próprios e pessoais.

Diante de tais particularidades, Delval (2002, 2013) empregando inúmeras investigações, em diferentes países e acerca de distintos conteúdos da realidade social apresentou que os indivíduos se adequam a essa natureza do conhecimento percorrendo três níveis de compreensão.

No primeiro nível, que ocorre até por volta dos 10-11 anos, os sujeitos baseiam suas ideias sempre por meio dos aspectos mais visíveis das situações em questão, desconsiderando processos ocultos e subjetivos, comuns às questões sociais.

As considerações sobre os conteúdos da realidade social são visões estereotipadas e simplistas. Além disso, não existe a coordenação de diferentes perspectivas e, desta forma, os conflitos decorrentes desta visão incompleta não são concebidos.

No que diz respeito ao segundo nível, que ocorre por volta dos 10-11 anos até os 13-14 anos, os sujeitos começam a levar em conta aspectos não visíveis das questões inicia-se a consideração de processos que precisam ser inferidos, mas a coordenação de diferentes pontos de vista ainda é algo difícil de ocorrer.

No terceiro nível, que se inicia aos 13-14 anos, apresenta explicações que revelam o conhecimento e a consideração de processos ocultos e mais, as diferentes perspectivas presentes em distintas situações passam a ser consideradas. Nesse momento, existe criticidade em relação à ordem e aos fenômenos sociais. 


\section{Metodologia}

O estudo caracteriza-se por ser de abordagem qualitativa. Assim, foram participantes 65 estudantes do curso de Pedagogia de uma Universidade Estadual paranaense, sendo 33 acadêmicos do primeiro ano e 32 pertencentes ao quarto e último ano dessa licenciatura. Entre os participantes, 6 acadêmicos são do sexo masculino e 59 do sexo feminino.

Ressalta-se a opção de tal recorte evolutivo, acadêmicos do primeiro e do quarto ano, em razão da busca pela existência de uma evolução de ideias entre os ingressantes e concluintes.

Para a coleta de dados, empreendeu-se a aplicação de um questionário, adaptado do instrumento já validado por Paganini-da-Silva (2015). As questões que o compuseram foram: 1) Qualquer pessoa pode ser professor?;2) Em sua opinião, como seria um bom professor? Defina com exemplos.; 3) Que tipo de dificuldade os professores enfrentam para exercer sua profissão?; 4) Você acha que tem ou não alguma diferença na função do professor se ele lida com a Educação Infantil, com o Ensino Fundamental I ( $1^{\circ}$ ao $5^{\circ}$ ano $)$ ou Ensino Fundamental II ( $6^{\circ}$ ao $9^{\circ}$ ano)? Por quê?;5) Você se sente realizado em sua escolha profissional? Por que escolheu o curso de Pedagogia?;6) Que imagem você mesmo tem de si mesmo como futuro professor?; 7) O que é ser professor para você?

Observa-se que todas as questões foram de caráter aberto, possibilitando aos participantes apresentar, livremente, suas ideias.

No decurso da realização da pesquisa, primeiramente, uma das pesquisadoras foi às salas de aula do $1^{\circ}$ e do $4^{\circ}$ ano de Pedagogia e informou os alunos sobre os objetivos da pesquisa. Neste mesmo momento, tais discentes foram convidados a participar da investigação e, logo após o devido consentimento, os questionários foram distribuídos para serem respondidos, de maneira individual. A pesquisadora acompanhou o preenchimento das respostas, tendo esta etapa duração média de 25 minutos. 
As respostas às questões foram analisadas à luz dos níveis de compreensão do conhecimento social (DELVAL, 2002; 2013) e, em específico, de acordo com os níveis construídos para a noção investigada, a identidade profissional docente, em consonância com Dubar (1997), Pimenta (1997), Arroyo (2000), Brzezinski (2002), Nóvoa (1991), dentre outros.

Cabe esclarecer que a escolha metodológica, de enquadrar as respostas dos participantes em níveis de compreensão do conhecimento social, ocorreu porque a perspectiva de desenvolvimento de Piaget não se limita a compreensão do pensamento das crianças, sobretudo, se nos debruçarmos a compreensão de mecanismos adjacentes ao estádio operatório formal, em tese, intrínsecos a um entendimento mais objetivo do conhecimento. Ademais, coerente com o presente estudo e corroborando Chakur (2001), essa perspectiva teórica pode alicerçar a compreensão da constituição e atuação de diferentes profissões, por tratar-se de uma parcela do mundo social que deve ser mais bem compreendida.

Ressalta-se que o próprio Piaget (1977), quando investiga os processos de tomada de consciência realiza-os em adultos e crianças ${ }^{3}$. A tomada de consciência, bem como a abstração reflexionante, são fundamentais para compreender o desenvolvimento, seja ele relacionado ao conhecimento físico, lógico matemático ou social.

Para o presente estudo serão apresentados os resultados das questões: Qualquer pessoa pode ser professor? Que imagem você tem de si mesmo como futuro professor? e O que é ser professor para você? A escolha destas deu-se pelo fato delas permitirem que sejam conhecidas as concepções mais ligadas a identidade docente propriamente dita.

\footnotetext{
${ }^{3}$ Na prova de andar de gatinhas, Piaget e seu colaborador, em 1970, submeteram à situação, convidados de um simpósio, todos adultos e foram constatadas respostas do nível I B (correspondente ao equilíbrio do estádio préoperatório).
} 


\section{Resultados e discussões}

As respostas dos participantes puderam ser enquadradas nos três níveis de compreensão da realidade social para a identidade docente. A fim de conhecer de forma mais analítica os tipos de respostas, optou-se por enquadrar as respostas de cada questionamento nos níveis de compreensão da realidade social. Assim tem־se:

\section{Questionamento “Qualquer pessoa pode ser professor?”}

As respostas que se aproximam ao nível 1 apresentam uma imagem docente que pauta-se apenas nos aspectos simplistas da profissão, por exemplo, na vocação ou dom e no amor em ensinar. Acompanha-se:

Não [...], pois nem todo mundo tem "vocação" e paciência para estar em uma sala de aula (Acadêmico do $1^{\circ}$ ano).

Não, porque é um dom ensinar e nem todos o tem (Acadêmico do $1^{o}$ ano).

Qualquer pessoa que esteja disposta a realizar um trabalho pautado no amor [...] (Acadêmico do $4^{o}$ ano).

O conjunto de respostas apresentado revela que esses futuros professores entendem a necessidade de aspectos afetivos para o exercício da atividade docente. São concepções que propagam ideias muito presentes no senso comum, isto é, no âmbito coletivo, de que existe um "dom", algo inato, que determina a aproximação do sujeito com determinada profissão. Desse modo, não demonstram ideias que compreendem o trabalho do professor como uma profissão, por isso, aspectos técnicos, tal como a necessidade de uma formação específica, não são considerados. 
As ideias apresentadas vão ao encontro das características do primeiro nível descritas na pesquisa de Guimarães (2007). Nesse estudo que investigou as concepções de escola, embora realizado com estudantes do fundamental I, com idades entre 7 e 8 anos foram reveladas respostas semelhantes às encontradas na presente pesquisa, tal qual o desejo pessoal como determinante para ser professor.

A partir do nível 2 de compreensão da realidade social, passa-se a considerar o aspecto formativo como algo importante. No entanto, questões de afetividade, afinidade e vocação são, ainda, determinantes, conforme se pode acompanhar nos excertos:

Não é simplesmente ter formação, tem que gostar de criança ou de estar em contato com pessoas. (Acadêmico do $1^{\circ}$ ano).

Não, como qualquer profissão além da capacitação é necessária vocação. (Acadêmico do $4^{o}$ ano).

Somente em presença do nível 3 de compreensão dessas questões, o ser professor, desvincula-se das questões afetivas e independem de dom ou vocação. Considera-se a exigência de uma formação específica e da compreensão dos processos de ensino e de aprendizagem. Em acréscimo, são concepções que reconhecem o papel social da profissão na formação de pessoas críticas e atuantes na sociedade. Tem-se como exemplo:

Sim, tem que estudar. Ser professor não é um dom é responsabilidade com o mundo e com seu futuro. (Acadêmico do $4^{o}$ ano).

[...]. Não é qualquer pessoa, precisa de estudo, qualificação, especialização, precisa entender como as pessoas aprendem. (Acadêmico do $4^{\circ}$ ano). 
As concepções que se entendem como mais apropriadas ao terceiro nível de compreensão da realidade social, deixam claro uma preocupação a mais dos acadêmicos, algo que está no âmago da profissão docente, e reflete sobre a importância dos processos relacionados ao ensino e aprendizagem.

Por meio das respostas que surgiram a esse primeiro questionamento é possível perceber que faz parte do ideário dos futuros docentes uma concepção de que o dom e a vocação são essenciais, ou melhor, são eles que marcam um profissional da educação. É fato que essa imagem acaba por definir de certa forma a identidade dos professores. Como afirma Arroyo (2000) "a ideia de vocação pode estar incrustada na ideia de profissão [...] por mais que tentemos apagar esse traço vocacional" esse se encontra junto à ideia de amor e dedicação como parte do "imaginário social e pessoal sobre o ser professor, educador, docente". (ARROYO, 2000, p. 33).

De modo semelhante, Nóvoa (1991) e Brzezinski (2002) também indicam tais características como constituintes da profissão docente. Para Brzezinski (2002) o próprio Ministério da Educação (MEC) reforça a ideia de que qualquer um pode ser professor, afirmando que pesquisas sobre avaliação institucional corroboram que não existe diferença entre os alunos formados por professores licenciados ou não.

Os resultados da frequência de respostas para cada um dos níveis de compreensão da noção social investigada podem ser acompanhados no gráfico 1 , a seguir. 
Gráfico 1: Frequência de respostas para a questão "Qualquer pessoa pode ser professor?"

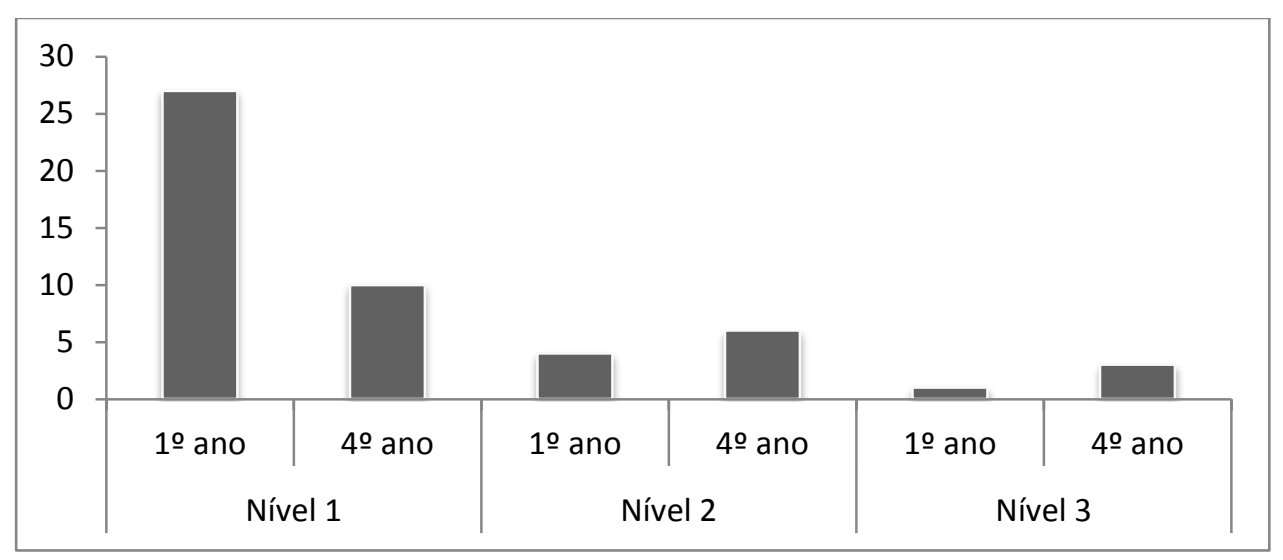

Fonte: Dados da pesquisa organizados pelas autoras.

Pode-se constatar que a maioria de respostas para essa questão enquadrou-se no primeiro nível, sobretudo, no que se refere aos acadêmicos do primeiro ano. Os concluintes dividiram-se, em grande maioria, em compreensões do primeiro e segundo ano. Apenas uma pequena parcela de sujeitos, e já acadêmicos do $4^{\circ}$ ano apresentaram uma concepção mais completa, presente no terceiro nível.

Esses são resultados importantes, pois mesmo tendo os acadêmicos iniciado e até mesmo vivenciado uma formação acadêmica específica para uma profissão, esta não é entendida como essencial para a formação profissional do professor. Em especial e relacionado aos participantes concluintes do curso de Pedagogia, questiona-se sobre o papel das disciplinas cursadas para a constituição de sua identidade docente, uma vez que em poucos casos, somente em respostas de segundo e terceiro nível, houve a preocupação com os processos de ensino e aprendizagem.

Tais apontamentos colaboram para refletir acerca do próximo questionamento, no qual solicitou-se aos participantes que indicassem a imagem que possuem deles, atuando como futuros professores. 


\section{Questionamento "Que imagem você tem de si mesmo como futuro professor?"}

Em resposta a essa questão, no primeiro nível estão as concepções que indicam a imagem de um futuro professor feliz, realizado e sem problemas. Por tratar-se de uma compreensão quase anedótica dos conteúdos sociais (DELVAL, 2002) surgem, mais uma vez, ideias de um professor atuante que ensina por amor e é sempre compreensível com seus alunos. Apresenta-se alguns excertos, em sequência.

Alguém que vai fazer o possível para ajudar as crianças, ensiná-las com todo carinho. (Acadêmico do $1^{\circ}$ ano).

[...] profissionalmente competente e realizado. (Acadêmico do $1^{o}$ ano).

Quero responder ao chamado, tentar compreender meu aluno [...] (Acadêmico do $4^{\circ}$ ano).

Os depoimentos apresentados sugerem uma ligação entre o instinto amoroso e maternal e a imagem de professor dedicado, assim como ressaltado anteriormente. Esta é, sem dúvida, uma das imagens recorrentes no senso comum, entre os leigos especialmente.

As respostas desse primeiro nível se assemelham muito às indicadas por Paganini-da-Silva (2006) quando investigou professores de $6^{\circ}$ ano $9^{\circ}$ anos. As imagens que surgiram em sua pesquisa foi a de "professor amigo; professor dedicado; professor competente; professor menteaberta/consciência; professor modelo" (p. 139).

Por ocasião do nível 2 de compreensão da realidade social, as ideias utópicas de um profissional realizado e capaz de resolver todos os problemas da educação ainda se mantem mas, passa-se a considerar que existem processos de ensino e aprendizagem que devem ser considerados e pondera- 
se sobre a necessidade de inovação na maneira de ensinar. Pensa-se sobre a necessidade de permanecer em formação contínua. Vejamos os depoimentos:

[...] pretendo ser dedicada ao objetivo de ensinar, fazendo atividades diferenciadas que facilitem a aprendizagem de meus alunos. (Acadêmico do $1^{\circ}$ ano).

Uma professora calma, atenciosa e preocupada com o desenvolvimento mental, moral e intelectual de cada aluno. (Acadêmico do $4^{\circ}$ ano).

Diante dos exemplos de respostas que ilustram o segundo nível, inferese que existe um avanço ao pensar na imagem profissional futura em comparação ao primeiro nível. Entretanto, como característico desse modo de compreensão, mais elementos são incorporados, mas ainda não permitem uma visão global e crítica da profissão.

Nas respostas que puderam ser reservadas ao nível 3 tem-se que os elementos relacionados à vontade desaparecem e considera-se a futura imagem profissional como uma construção, um aprendizado constante. Existe a clareza da necessidade de relações de diálogo com os alunos, isto é, busca-se ser um profissional que contextualiza o ensino, bem como apresenta uma atuação docente que almeja a diversificação de estratégias didáticas.

Ainda não tenho imagem, pois penso que a cada dia vou construir a minha identidade como professor. (Acadêmico do $1^{\circ}$ ano).

[...] dialogando, fazendo atividades diferenciadas. (Acadêmico do $4^{o}$ ano).

Uma professora aberta a questionamentos novos e estudos que irão ampliar minha área de atuação. (Acadêmico do $4^{o}$ ano). 
Surpreende a resposta de um acadêmico ingressante, presente no primeiro excerto apresentado, o entrevistado afirma que a imagem profissional não é algo pronto e acabado, mas que se constrói no dia-a-dia.

De maneira geral, as concepções encontradas para o segundo questionamento remetem as considerações de Dubar (1997) sobre a identidade social que é constituída tendo em vista uma identidade para si que depende do olhar do outro, pois é este que reflete nossa própria imagem. Cabe ressaltar que a experiência do outro nunca é diretamente vivida por si, e, por conta disso, acaba-se por forjar uma identidade para nós próprios.

Complementa-se com Gauthieret al. (1998) ao indicarem como um saber docente, uma das imagens que aparecem nas respostas dos acadêmicos que é o professor-competente. De acordo com essa crença para ser um bom professor é necessário apenas conhecer e dominar o conteúdo. No entanto, para os autores os saberes docentes não podem ser reduzidos à pura transmissão de conhecimento, pois ser professor é muito mais que isso, de modo que envolve e requer uma série de habilidades e competências.

Vale retomar que as imagens docentes sofrem alterações no decorrer da história e estas deixam resquícios na imagem atual dessa categoria. As imagens públicas dos professores são construídas nas disputas que se estabelecem no campo educacional, inclusive com relação aos currículos, como assegura Arroyo (2014), nas relações de grupo e movimentos que procuram um maior reconhecimento de seu trabalho diante de outras categorias profissionais.

É interessante ressaltar uma situação específica e pontual desse trabalho. Em 4 questionários dos alunos do $4^{\circ}$ ano não foi possível determinar o nível de compreensão da realidade social para esse questionamento, pois os alunos afirmaram não conseguir fazer uma imagem profissional futura, seja pela incerteza em atuar na educação, seja pela demonstração de desânimo com a futura profissão. 
As frequências de respostas desse segundo questionamento podem ser acompanhadas por meio do gráfico 2 , em sequência.

Gráfico 2 : Frequência de respostas para a questão "Que imagem você tem de si mesmo como futuro professor?"

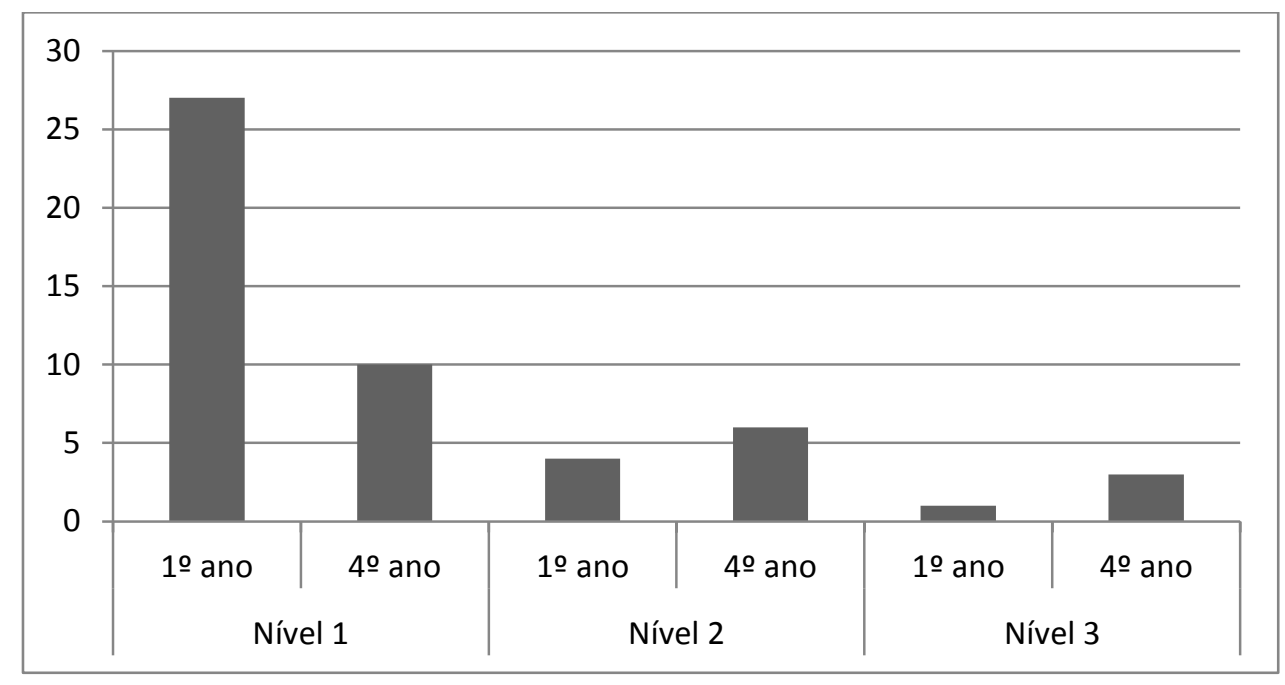

Fonte: Dados da pesquisa organizados pelas autoras.

As frequências apresentadas mostram que os participantes, em sua maioria, apresentam respostas cujo conteúdo aproxima-se a compressão do primeiro nível, mesmo em acadêmicos do quarto ano. Diante disso, ressaltase o quanto concepções presentes na sociedade, por exemplo, a ideia de quem tem uma profissão é bem sucedido e realizado, são enraizadas não permitindo que outros elementos sejam incorporados à reflexão e constituição da imagem profissional docente. 


\section{Questionamento "O que é ser professor para você?"}

Objetivou-se nessa questão conhecer, de fato, a concepção que permeia o imaginário de nossos participantes acerca da atuação docente. Sendo assim, no nível 1, encontrou-se ideias ligadas apenas a transmissão de conhecimentos, a qual caracterizaria o "ser professor". Também aparecem pensamentos ligados à função de cuidado e zelo pelas crianças, conforme podemos acompanhar, a seguir.

Passar para os alunos os conhecimentos que adquiriu na sua vida. (Acadêmico do $1^{\circ}$ ano).

Ser mediador do conhecimento [...]. (Acadêmico do $4^{o}$ ano).

Cuidar, ensinar e amar [...]. (Acadêmico do $4^{\circ}$ ano).

No nível 2, passa-se a perceber que o ensinar não é somente a transmissão de conteúdos e concebe-se que as pessoas aprendem de maneiras diferentes, por isso a função está mais próxima aos saberes de uma profissão específica. É o caso das afirmações, em sequência.

Ser professor é transmitir o saber, o conhecimento para aquele que quer aprender, é incentivar a aprendizagem. (Acadêmico do $1^{o}$ ano).

[...] transmitir conhecimento com comprometimento [...] utilizando diversos recursos para que o aprendizado aconteça. (Acadêmico do $4^{\circ}$ ano).

Somente no terceiro nível de compreensão da realidade socialos sujeitos compreendem que é importante e necessário escolher a melhor didática para que a aprendizagem ocorra, ou seja, a preocupação é com a aprendizagem e 
não apenas com a transmissão de conhecimentos. Nesse momento existe uma posição mais reflexiva com relação a função docente sendo representado por um olhar sob diferentes perspectivas para o exercício da profissão, por exemplo, o professor tem consciência de que ele precisa encaminhar seu aluno ao "aprender a aprender". Pode-se acompanhar tal compreensão nos excertos que afirmam:

Transformar pessoas em seres melhores, trazendo novas chances e oportunidades para seu futuro. (Acadêmico do $1^{\circ}$ ano).

$A$ função de ensinar é mediar, tornar o aluno autônomo $e$ independente, o professor precisa tornar seu aluno questionador, crítico, fazendo com que busque conhecimento, e sinta vontade de aprender, não por obrigação e sim por "descobertas", o professor deve mostrar ao aluno caminhos além do que ele está vendo. (Acadêmico do $4^{o}$ ano).

No gráfico 3, a seguir, apresenta-se a frequência de respostas encontradas em cada nos anos pesquisados.

Gráfico 3: Frequência de respostas para a questão "O que é ser professor para você?"

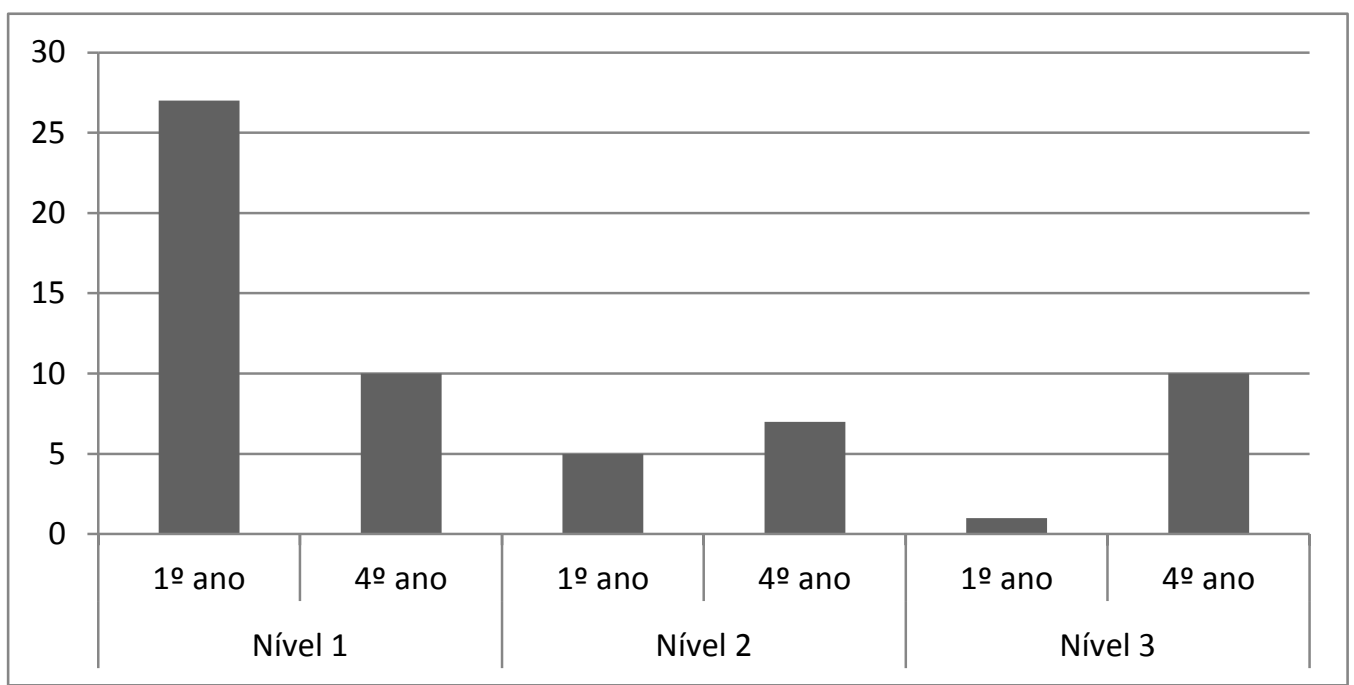


Fonte: Dados da pesquisa organizados pelas autoras.

No que tange aos resultados desse questionamento, é possível acompanhar que os acadêmicos ingressantes concentram suas ideias na compreensão de que a atuação do professor relaciona-se apenas da transmissão de conhecimentos, sem levar em conta demais aspectos presentes no processo educativo. Essa constatação aproxima-se do observado em Paganini-da-Silva (2006) com relação aos professores já em serviço.

Nesse particular, chama atenção as respostas dos acadêmicos concluintes, uma vez que puderam ser enquadradas em compreensões de nível 2 e 3 , o que revela um maior conhecimento do papel profissional do professor. Acredita-se que esse resultado é decorrente do fato dos acadêmicos quartanistas já terem tido maior contato com a profissão, sobretudo, por meio dos estágios obrigatórios, ao longo do curso.

De certo modo, tais momentos e os demais presentes em sua formação permitiram, para a maior parte dos discentes, reflexões sobre a consciência de seu papel, isto é, afere-seque a formação inicial é extremamente importante, mas, além disso, há a necessidade de ela possuir qualidade e uma fundamentação pedagógica que ultrapasse os requisitos técnicos.

No entanto é preciso considerar que:

A dificuldade de definição das atribuições do professor acaba por levar à incorporação de uma multiplicidade de tarefas que, muitas vezes, ultrapassam a função docente, fugindo de seu alcance e caracterizando atividades de profissões ou ocupações distintas das do magistério. Sabemos que a identidade profissional docente diz respeito ao modo como os professores se veem e como são vistos pelos outros; diz respeito ao próprio trabalho, ao valor social que possuem ou não, a seus saberes e à sua competência para ensinar. (PAGANINI-DA-SILVA, 2006, p. 210). 
Esta questão trazia de forma mais direta o tema da presente pesquisa impulsionando os acadêmicos a pensar a respeito da função e identidade docente. Para Gimeno Sacristán (1991) a função docente encontra-se em permanente elaboração e depende diretamente das relações e dos contextos sociais nos quais a comunidade docente se encontra.

Tendo isso em mente, ressalta-se que os sujeitos investigados são acadêmicos do curso de Pedagogia e, por isso, sua identidade não poderia e nem deveria estar formada por completo. Entretanto, considerando a participação de acadêmicos do último ano de curso esperava-se que a construção da identidade, a qual deveria ser promovida pela formação inicial apresentasse mais elementos próximos ao nível 3 de compreensão da realidade social, isto é, de uma forma mais elaborada de pensar os conteúdos dessa natureza.

\section{Conclusões}

A pesquisa apresentada teve por objetivo conhecer as concepções de estudantes ingressantes e concluintes do curso de Pedagogia a respeito da identidade docente, isto é, do papel do professor. Para tanto apresentou-se os resultados obtidos a três questionamentos realizados que investigaram se os estudantes concebiam que qualquer pessoa poderia ser professor, como eles se imaginavam no futuro ao atuar na profissão escolhida e, por fim, qual seria o papel do professor.

A hipótese que permeou o presente estudo é a que esse é um tema de natureza social, construído por meio das relações que se estabelecem com esse objeto de conhecimento específico, por isso, haveria uma evolução de respostas. Desse modo, acreditou-se que os participantes matriculados no primeiro ano apresentariam respostas mais elementares e características do primeiro nível de compreensão da realidade social, já os participantes concluintes do curso revelariam ideias mais elaboradas, que poderiam ser enquadradas no terceiro nível. 
Ao longo da análise qualitativa apresentada observa-se que a hipótese revelada foi, sutilmente, confirmada, haja vista que somente em um dos questionamentos a evolução das ideias, entre primeiranistas e quartanistas, pôde ser melhor observada.

Assim, a concepção mais presente para a indagação se qualquer pessoa poderia ser professor, foi a do nível 1, isto revela que é muito presente entre os acadêmicos pesquisados, ideias mais simplistas, por meio das quais entende-se que a atuação docente depende muito mais de aspectos afetivos, tais como gostar de crianças e ter o dom de ensinar, do que a aspectos técnicos e adjacentes à profissão.

De modo semelhante, no que se refere à imagem profissional, encontrou-se a maioria das respostas enquadradas no primeiro nível de compreensão, revelando que ao conceberem sua atuação enquanto profissionais da educação, os futuros professores, imaginam-se bemsucedidos, felizes e capazes de resolver os problemas que surgirão. De maneira alguma, defende-se que a atuação profissional não pode apresentar essas características, mas entende-se que é preciso pensar em todos os aspectos que, de maneira intrínseca, passam pela atuação docente, por exemplo, questões ligadas às políticas públicas, ao currículo, às condições de trabalho docente, entre outras.

Destarte, quanto às respostas encontradas para o questionamento sobre o ser professor foram encontrados resultados mais positivos e que corroboram a hipótese inicial. Assim, os alunos de primeiro ano mostram-se presos a aspectos mais visíveis e estereotipados da profissão, típico do primeiro nível, já os de quarto ano, apresentaram, ainda, essa concepção, mas a maior parte das respostas dividiu-se entre o segundo e o terceiro nível, indicando que aspectos mais subjetivos e que precisam ser levados em conta para a construção da identidade docente, passaram a ser considerados.

Novamente é preciso deixar claro que para nenhuma das questões desconsidera-se a importância de um professor gostar do que faz ou ser dedicado à sua profissão, apenas não é possível entender como concepção 
mais "evoluída" respostas que centraram-se apenas em um único aspecto da docência e de sua constituição identitária, deixando de perceber sua totalidade.

Os professores deveriam se expor mais à sociedade sendo importante essa comunicação e se aproximando mais dos problemas e da realidade escolar trocando experiências com seus pares, atuando mais como pesquisadores e menos como meros executores. Nesse sentido, pensando no desenvolvimento profissional dos professores sob a ótica piagetiana, é possível afirmar a relevância dessas trocas na expectativa de promover reflexão acerca dos problemas e, ainda, causar desequilíbrios e equilíbrios posteriores em relação à sua prática.

Essa pesquisa não esgota a temática, mas fornece subsídios para a reflexão acerca desse conhecimento social, sobretudo, no que se refere a formação inicial docente, uma vez que essa é essencial para a construção do ser professor. Ressalta-se a necessidade de voltar-se a atenção aos cursos de licenciatura, com sua qualidade, promovendo contextualizações sobre a profissão docente, algo que nem sempre é considerado nessa etapa de formação.

\section{Referências}

ARROYO, M. G. Ofício de mestre: imagens e auto-imagens. 3. ed. Petrópolis: Vozes, 2000 .

Currículo, território em disputa. Petrópolis: Vozes, 2014.

BERGER, P. L.; LUCKMANN, T.A construção social da realidade: tratado de sociologia do conhecimento. Petrópolis: Vozes, 1985.

BRZEZINSKI, I. (Org.). Profissão professor: identidade e profissionalização docente. Brasília: Editora Plano, 2002.

CHAKUR, C. R. S. L. Desenvolvimento profissional docente: contribuições de uma leitura piagetiana. Araraquara: JM Editora, 2001.

DELVAL, J. Introdução à prática do método clínico: descobrindo o pensamento da criança. Tradução de Fátima Murad. Porto Alegre: Artmed, 2002. 
DUBAR, C. A socialização: construção das identidades sociais e profissionais. Porto: Porto Editora, 1997.

ENESCO, I. et al. La comprensión de la organización social en niños y adolescentes. Madrid: CIDE, 1995.

LIBÂNEO, J. C.; PIMENTA, S. G. Formação dos profissionais da educação: visão crítica e perspectivas de mudança. Educação \& Sociedade, Campinas, ano XX, n. 68, 1999.

GAUTHIER, C. et al. Por uma teoria da pedagogia: pesquisas contemporâneas sobre o saber docente. Ijuí: Unijuí, 1998.

GIMENO SACRISTÁN, J. Consciência e acção sobre a prática como libertação profissional dos professores. In: NÓVOA, A. Profissão Professor. Porto: Porto Editora, 1991, p.61-92.

GIDDENS, A. Modernidade e Identidade. Rio de Janeiro: Zahar, 2002.

GUIMARÃES, T. As ideias infantis a respeito da escola e do professor: um estudo comparativo acerca da construção do conhecimento social em ambiente sócio-morais construtivistas e ambientes tradicionais. $120 \mathrm{f}$. Trabalho de conclusão de curso (Graduação em Pedagogia) - Faculdade de Filosofia e Ciências, Universidade Estadual Paulista "Júlio de Mesquita Filho", Marília, 2007.

NÓVOA, A. Para o estudo sócio histórico da gênese e desenvolvimento da profissão docente. Teoria \& Educação, Porto Alegre, n. 4, p. 109-139, 1991.

em:

Professores: imagens do futuro presente. Educa. Lisboa, 2009. Disponível

http://www.etepb.com.br/arq_news/2012texto_professores imagens do futuro pres ente.pdf. Acesso em: 25 out. 2012.

PIMENTA, S. G. Formação de Professores - Saberes da docência e identidade do professor. Nuances, Presidente Prudente, v. 3, p. 5-14, 1997.

De professores, pesquisa e didática. Papirus: Campinas, 2002.

ROGERS, C. Tornar-se pessoa. São Paulo: Martins Fontes, 1972.

PAGANINI-DA-SILVA, E. A profissionalização docente: identidade e crise. 2006. 221f. Dissertação (Mestrado em Educação Escolar) - Universidade Estadual Paulista "Júlio de Mesquita Filho", Araraquara, 2006.

Ser professor e a relação ensino-aprendizagem: uma contribuição piagetiana. $253 \mathrm{f}$. Tese (Doutorado em Educação) - Universidade Estadual Paulista "Júlio de Mesquita Filho", Marília, 2015.

VIANNA, C. Os nós do "nós": crise e perspectiva da ação coletiva docente em São 
Paulo. São Paulo: Xamã, 1999.

Recebido em 27 de setembro de 2017. Aprovado em 12 de janeiro de 2018. 